\title{
CHANGING PIGMENT TREND OF FUNGI AT THE TIME OF ANTAGONISTIC ACTIVITY
}

\author{
Chhaya Nilakantha Lanje \\ Department of Household Biology, \\ S. Chandra Mahila Mahavidyalaya Sadak /Arjuni, Distt - Gondia (M.S) India - 441807 \\ Email- chhayalanje@gmail.com
}

Communicated: 30.11 .20

\begin{abstract}
:
The present study deals with the diversity of fungal communities associated with the leaf surface of sugarcane. The frequency of fungal biodiversity differed significantly between the wet and dry season. Morphologically fungal colonies create a variety of colour. Demonstrate diversity of fungal colour. Screening of phylloplane mycoflora shows the variety and galaxy of fungi as well as the natural beauty of the fungal ecosystem. The climate of Gondia district is tropical hot and constructive for growth of fungi. The colour of mycoflora is due to different coloured substances in the cells. The fungi absorb light of different wavelengths creating natural colours (purple, pink, green, yellow, orange and brown) of conidia.
\end{abstract}

Key words: - fungal, mycoflora, colour, sugarcane, diversity, pigment.

\section{INTRODUCTION:}

Natural dyes are non-toxic, non-polluting and less health perilous. Moreover, their antioxidant and antimicrobial nature further adds to their positive effects. Natural dyes can be obtained from various sources like plants, animals and microbes. Number of other Colletotrichum species such as C.gloeosporioides (Verma, 1973), C. acutatum (Kaur and Singh, 1990) and C. coccodes (Oh etal., 1988; Yu etal., 1987) have been associated with the disease in different geographical areas. The use of fungi to control the disease will be helpful for upcoming practices. Antagonistic activity of these isolates with the Collectotrichum graminicola will be a potent source of fungicides.

Colour diversity also observed in fungal culture. In present study of mycology showed a variety of colour in Petri dish because fungi contain phytochemicals that can make the textile industries.

\section{MATERIAL \& METHODS:}

Screening of phylloplane mycoflora on sugarcane for colour diversity study by both direct and indirect methods.

\section{DIRECT METHOD:}

A) Field Observation: Survey has been carried out monthly to observe the disease and photographs were taken with the help of Nikon digital camera (6.0 megapixels). It gives direct images of objects on screen.

b) Laboratory Observation: Infected leaves observed and collected in sterile segregate polyethylene bags as per infected morphological appearance from different areas randomly within a month interval. Laboratory section done by section cutting of infected yellow and green leaves. 1\% aqueous solution of lactophenol cotton blue was used as stain and microscopic photographs also taken.

c) Pigment Production: Cultures of Trichoderma viride, Curvularia lunata and Alternaria alternate were grown on PDA (potato dextrose agar). All the flasks were incubated at 
$37^{\circ} \mathrm{C}$ for pigment production. Fungal culture broths showing colour were filtered out after three weeks.

\section{INDIRECT METHOD:}

Infected leaf is cut into $2 \mathrm{~cm}$ pieces and washed with tap water then transferred into $0.1 \%$ mercuric chloride $\left(\mathrm{HgCl}_{2}\right)$. Infected leaf pieces transferred into flask containing $100 \mathrm{ml}$ sterile distilled water and washed serially for 5 - 6 times with changing sterile distilled water in aseptic condition. These small leaf pieces about $2 \mathrm{~cm}$ long were transferred on sterile filter paper so as the blot dried for inoculation.

\section{CULTURE OF FUNGI: Spot inoculation} method (Adams, 1990)

Washed and blot dried leaf pieces transferred on to surface of culture media (Zapak Agar Dox) in Petri dishes by spot inoculation method (Adams, 1990) were incubated at room temperature $25 \pm 20^{\circ} \mathrm{C}$.

\section{RESULTS AND DISCUSSION:}

Some of Fungus Identified through Agharkar Research Institute as follows,

\section{Colour and Discharge of Culture:}

Pigments are fermentative products so they are affected by temperature, $\mathrm{pH}$, carbon source, aeration and type of fermentation (solid or submerged). Pigment anthraquinone is widely used in the dyestuff industry and most commonly produced by Trichoderma, Aspergillus, and Fusarium (Duran etal., 2002).

Aspergillus niger colonies spread rapidly with mycelium white to dark brown to black and conidial heads globose. The colour of the meeting point changes when a $C$. graminicola fungus meets Aspergillus niger. The dark blackish maroon colour zone is prepared because fungi loss their original pigmentation. All fungus colour variations and changed after the antagonistic action are given below.
Many scientists are working on pigments. This pigment is not harmful to the environment due to it being completely natural. In the above table, we have given about the original discharge (Pigment) of fungi and it to be changed after the antagonistic action.

Members of different genera of the fungal family Pleosporaceae (Alternaria, Curvularia, Pyrenophora, etc.) have immense potential for pigment production. Species of Alternaria such as Alternaria alternata, Alternaria solani, Alternaria porri, and Alternaria tomatophila have been reported to produce a variety of pigments such as dactylariol, alterperylenol, dihydroalterperylenol, alternariol, alternariol 5 methyl ether, altenuene, alternarienoic acid, tenuazoic acid, stemphyperylenol, and altersolanol (Ajay C. Lagashetti and etal., (2019).

In present study Alternaria alternata shows golden brown conidia. Cladosporium cladosporioides are velvety, light olive green to olive green. Yellow colony of Epicoccumnigrum is fast growing on the media and shows brown to yellow colour. Fusarium moniliforme and $F$. oxysporumis very fast growing fungi. Colony is white and starts becoming pink in colour shows moderate growth.

Mukherji G. etal., (2017) reported many fungi whose pigments are now considered as safe and economical. Fungi like Aspergillus, Fusarium, Trichoderma, and Laetiporus are reported to produce quinones, anthraquinones, Rubropuntamine, Rubropuntatin, Ankaflavin, Monascin, $\beta$ carotene, and many other pigments responsible for various colours, viz. red, purple, yellow, brown, orange and green.

Antagonists are of potential value in studies of the mechanism of action of biologically active 
compounds, being used to block the function of the agonists.

\section{CONCLUSIONS}

The colors of fungus vary depending on different phytochemicals. All colours of fungi (Red, black, yellow, orange, pink, white, purple, olive) are created by dissimilar pigments like melanin, carotenoids, chromanone, quinones, anthraquinones etc. Mycology is a wonderful source of colour inspiration. The colors of fungus vary depending on different phytochemicals. From antagonistic studies we get to know that fungi can work as a biocontrol for farm and can be used in business like textile industry. Through the antagonistic study of fungi, we can also prepare color combinations as well as it is one of the highest potential approaches for plant disease control since it is advantage of safety and environmental friendly. This Pigment of Trichoderma viride, Alternaria alternata and Curvularia lunata can be used for future practices in textile.

\section{ACKNOWLEDGEMENT :}

The authors gratefully acknowledge the laboratory facilities of Hislop College, Nagpur and Jagat Arts, Commerce and Indiraben Hariharbhai Patel Science College Goregoan as well as some fungus identified with the help of NFCCI by Agharkar Research Institute (An Autonomus Grand in Aid Institute under the Department of Science and Technology, Govt. of India) during the course of this research.

\section{REFERENCES:}

Adams, P. B. (1990): The potential of mycoparasites for biological control of plant disease. Ann. Rev. Phytopathol. vol 28:Pp. 59-72.

Ajay, C., Lagashetti, Laurent Dufosse, Sanjay K., Singh and Paras N., Singh. (2019): Fungal Pigments and Their Prospects in Different Industries. Microorganisms. vol 7(12): Pp. 604

Duran, N., Teixeira, MFS, De Conti, R., Esposito, E. (2002): Ecological-friendly pigments from fungi. Crit Rev Food Sci Nutr. vol 42:Pp. 53-66.

Kaur, S., and Singh, J. (1990): Colletotrichum acutatum a new threat to Chilli crop in Punjab. Indian phytopathology. vol 43:Pp103-110.

Mukharji Gunjan, Mishra Tulika and Deshmukh Sunil. (2017):Fungal Pigment: An Overview. Development in fungal biology and applied mycology. Book Chapter 19-21:Pp. 525- 541.

Oh IS., In MS, Woo TS, Lee SK and Yu SH. (1988): Anthracnose of Pepper seedling caused by Colletotrichum coccodes. Korean J. Mycology. vol 16: Pp.151-156.

Verma, M. C. (1973): Comparative Studies on Virulence of isolates of Four species of Colletotrichum Parasitic on Chillies. Indian phytopathology. Vol 24:Pp.28331.

Yu, S. H., Park, J. S., Oh, I. S., Wu, I. S. and Mathur, S. B. (1987): Colletotrichum Coccodes found in seeds of Capsicumannum and Pathogenicity of Solanaceae Plant. Korean J. Mycology. vol 15: Pp183-186. 
I J R B A T, Issue (IX), Vol. I, Jan 2021: 08-11

\begin{tabular}{|l|l|l|l|}
\hline Sr. No. & Culture & NFCCI Accession & Identification Remarks \\
\hline 1. & 'A' & NFCCI-3376 & Cladosporium cladosporioides (Fersen.) De Vrise \\
\hline 2. & 'B' & NFCCI-3377 & Leptoxyphium sp. \\
\hline 3. & 'C' & NFCCI-3378 & Fusarium aff. Fusarioides (Frag. \& Cif.) Booth \\
\hline 4. & 'D' & NFCCI-3379 & Penicillum oxalicum Currie. \& Thoom. \\
\hline
\end{tabular}

Table -1: Colour variations before and after the antagonistic action

\begin{tabular}{|c|c|c|c|}
\hline Sr.No. & Name of Fungi & $\begin{array}{l}\text { Original colour } \\
\text { (Discharge) }\end{array}$ & $\begin{array}{l}\text { Changing pigment after antagonistic } \\
\text { (morphological observation) }\end{array}$ \\
\hline 1. & Aspergillus niger (Van. Tieghem) & Creamish & Maroon \\
\hline 3. & Mucor globous (Fischer) & Greyish black & Maroon \\
\hline 4. & $\begin{array}{l}\text { Fusarium oxysporum (Schl. et. al., } \\
\text { Domesh) }\end{array}$ & Whitish pink & Cream \\
\hline 5. & Penicillium radicum & Greenish orange & Greyish black \\
\hline 6. & P. rubrum (Stoll) & Light green & Cream \\
\hline 7. & $\begin{array}{lll}\text { Trichoderma } & \text { viride } & \text { (Persi) } \\
\text { Subramanian } & & \\
\end{array}$ & Green & Light Maroon \\
\hline 10. & Alternaria alternate (Fr.) Keissl & Greenish grey & Grey \\
\hline 11. & Botrytis cinerea (Persoon) & Reddish & Black \\
\hline 12. & Eurotium glomus & Yellow & White \\
\hline 13. & Pestalotiamacrotricha (Kleb) & White & White \\
\hline
\end{tabular}

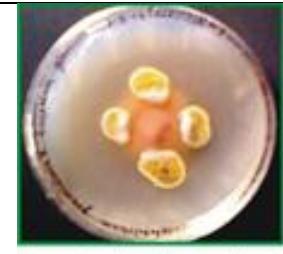

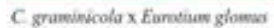

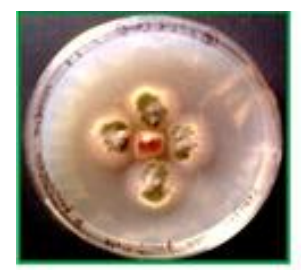

C. graminicola x Penicillian rubrum

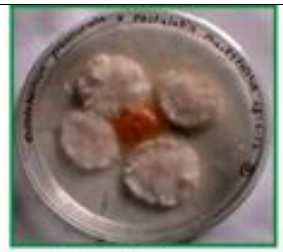

Cgruminicola x Pestatotia macrouricha

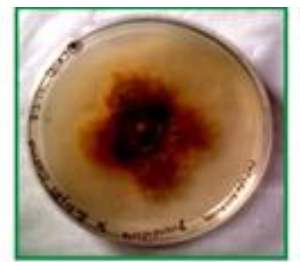

C. graminicala $\times$ Botnytis ciserea
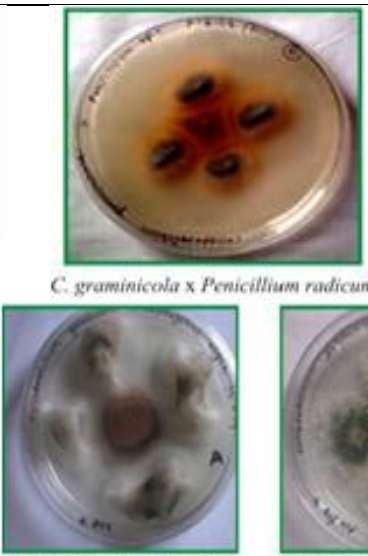

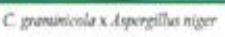

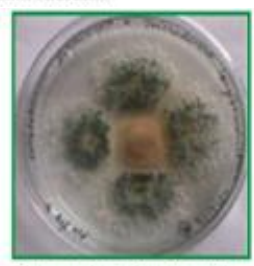

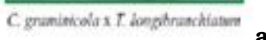

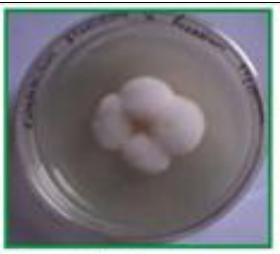

Cigruminicolo x Funarian ensponam

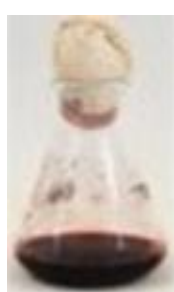

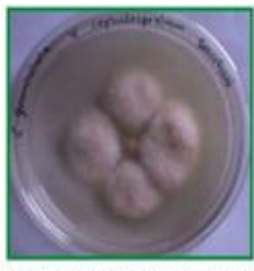

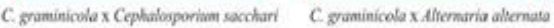

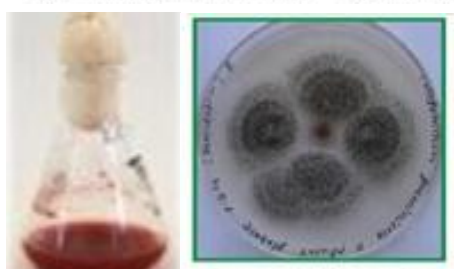

b.

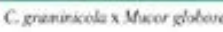

a. Discharge of Curvularia lunata

b. Discharge of Alternaria alternate

c. Fig - Colour and Discharge of Culture 